https://nv.nltu.edu.ua

https://doi.org/10.15421/40290520

$@ \bowtie$ Correspondence author

Article received 17.05.2019 p.

Article accepted 30.05.2019 p.

S. M. Shakhov

УДК 614.841

lophennss@gmail.com

С. М. Шахов' , А. І. Кодрик', О. Ф. Нікулін ${ }^{2}$, О. М. Тітенко ${ }^{2}$, С. А. Виноградов 1 , І. Г. Стилик ${ }^{2}$

${ }^{1}$ Національний університет циивільного захисту України, м. Харків, Україна

${ }^{2}$ Український науково-дослідний інститут ијивільного захисту, м. Київ, Украйна

\title{
ВИЗНАЧЕННЯ ЗАЛЕЖНОСТІ ХАРАКТЕРИСТИК КОМПРЕСІЙНОЇ ПІНИ
}

Проведено теоретичне обгрунтування залежності експлуатаційних характеристик компресійної піни залежно від геометричних розмірів та однорідності бульбашок, що ії утворюють. Введено поняття умовної відносної міцності бульбашки як величину відношення площі центрального поперечного перетину бульбашки до ії маси бульбашки та наведено формули для його вирахування. Наведено експериментальні залежності експлуатаційних характеристик компресійної піни від геометричних розмірів та гомогенності міхурів, що їі утворюють, що дає змогу створювати ефективні системи 3 утворення КП та здійснювати управління процесами піноутворення та пожежогасіння. Результати досліджень підтверджують, що величини діаметрів міхурів КП та їхня гомогенність, що характеризується полідисперсністю піни, визначають їі кратність, яка визначає стійкість та адгезійні властивості піни. У разі збільшення кратності піни, полідисперсність зменшується, тобто гомогенність зростає. Доведено, що існує прямий зв'язок між експлуатаційними характеристиками компресійної піни, такими як: стійкість піни, адгезійна властивість піни, вогнегасна здатність піни та ії геометричними характеристиками - розмірами бульбашок та їхня гомогенністю, при чому розміри міхурів та їх гомогенність (полідисперсність) є визначальними параметрами компресійної піни щодо іiї експлуатаційних характеристик. Технологічні рішення, спрямовані на зменшення розміру бульбашок піни та підвищення її однорідності призведуть до покращення експлуатаційних характеристик компресійної піни та її подальшого впровадження для підвищення ефективності гасіння лісних пожеж.

Ключові слова: компресійна піна; розміри бульбашок; однорідність; стійкість піни; лісові пожежі.

Вступ. Відомо, що одним із важливих чинників, який надає збиток лісовим ресурсам, є виникнення пожеж. Переважно під час гасіння твердих горючих речовин, а саме деревини, часто використовують воду, через iii дешевизну і простоту використання. Цей вогнегасний засіб має низку недоліків і одним з перспективних напрямів підвищення ефективності боротьби з вогнем у лісових масивах пропонується застосування компресійної піни (Zalesov, Godovalov \& Krektunov, 2014). Технологія використання такої піни значно поширена за кордоном і застосовують вже протягом кількох десятків років. На відміну від звичайної піну, вона має особливі, які не характерні для звичайної піні властивості, а саме: підвішену стійкість, посилену адгезію та вогнегасну здатність під час одночасного зменшення витрат води і піноутворювача (Taylor, 1998; CAFS, 2008; Neal Brooks). Це пов'язують зі зменшення діаметрів бульбашок компресійної піни, порівняно 3 повітряно-механічною

піною, та підвіщенням однорідності. Відомо, що розміри бульбашок КП та їхня однорідність (Adamson, 1997; Nikulin, Kodrik \& Titenko, 2018) залежать від методів їх утворення, типу і концентрації піноутворювача (далі ПУ), наявності стабілізаційної речовини, співвідношення витрат водного розчину ПУ і повітря, зміна яких повинна забезпечувати створення піни, яка має належні властивості для боротьба 3 горінням певного класу пожеж і залишається стабільною.

Мета дослідження - виявити залежність експлуатаційних характеристик компресійної піни від геометричних розмірів та однорідності бульбашок, що ії утворюють, що дасть змогу створювати ефективні системи з утворення КП та здійснювати управління процесами піноутворення та пожежогасіння з метою їх подальшого застосування для гасіння пожеж у лісних масивах України.

Наукові передумови для роботи - згідно з (GOST R 50588, 2012), середній розмір бульбашок піни серед-

Інформація про авторів:

Шахов Станіслав Михайлович, ад'юнкт, кафедра інженерної та аварійно-рятувальної техніки.

Email: lophennss@gmail.com; https://orcid.org/0000-0003-3914-2914

Кодрик Анатолій Іванович, канд. техн. наук, начальник відділу інноваційних технологій. Email: kodrik@ukr.net; https://orcid.org/0000-0002-3787-5674

Нікулін Олександр Федорович, д-р техн. наук, начальник науково-дослідного центру інноваційних технологій. Email: a.f.nikulin@gmail.com; https://orcid.org/0000-0001-9126-0681

Тітенко Олександр Миколайович, канд. техн. наук, ст. наук. співробітник, відділ інноваційних технологій. Email: titenkoalex1954@gmail.com; https://orcid.org/0000-0002-4950-8580

Виноградов Станіслав Андрійович, канд. техн. наук, доцент, кафедра інженерної та аварійно-рятувальної техніки. Email: vynogradovs@gmail.com; https://orcid.org/0000-0003-2569-5489

Стилик Iгор Геннадійович, інженер, сектор метрологіï. Email: stilik_i@undicz.dsns.gov.ua; https://orcid.org/0000-0002-8474-2014

Цитування за ДСту: Шахов С. М., Кодрик А. І., Нікулін О. Ф., Тітенко О. М., Виноградов С. А., Стилик І. Г. Визначення залежності характеристик компресійної піни. Науковий вісник НЛтУ України. 2019, т. 29, № 5. С. 103-106.

Citation APA: Shakhov, S. M., Kodryk, A. I., Nikulin, O. F., Titenko, O. M., Vinogradov, S. A., \& Stylyk, I. G. (2019). Determination of the dependence of compression foam characteristics. Scientific Bulletin of UNFU, 29(5), 103-106. https://doi.org/10.15421/40290520 
ньої та низької кратності піноутворювачів загального призначення знаходиться у межах від 2 до 5 мм. Використовуючи спеціальні ПУ, можливо отримувати таку піну з розмірами бульбашок від 1,8 до 2,5 мм. Щодо однорідності бульбашок - інформація не надається. Згідно 3 інформацією в іноземних джерелах, орієнтовний розмір бульбашок КП повинен бути не більше ніж 0,60,8 мм. Автори (Dorau, 2012) стверджують, що "піна хорошої якості є однорідна, складається з дуже маленьких бульбашок, які, наприклад, мають середній еквівалентний діаметр в інтервалі від 0,5 до 1 мм". У попередніх дослідженнях (Nikulin, Kodrik \& Titenko, 2018) отримана нами КП складалася 3 бульбашок діаметром від 0,08 до 0,2 мм, (рис. 1), що значно менше від зазначених вище і що повинно позитивно впливати на характеристики якості піни, наприклад на їі стійкість. Стійкість такої компресійної піни повинна зростати під час зменшення діаметра бульбашки.

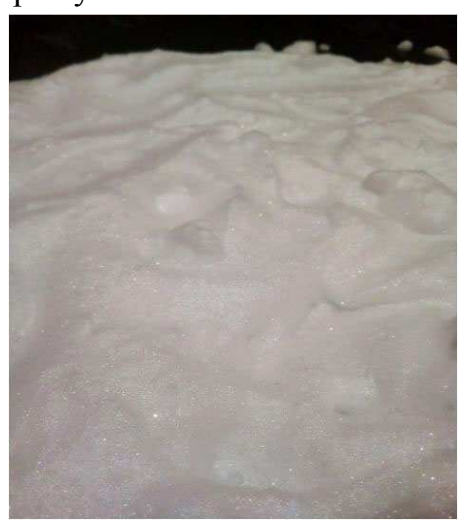

Рис. 1. Загальний вигляд компресійної піни, діаметр бульбашок від 0,08 до 0,2 мм

Підвищення стійкості пов'язано з особливістю фізичних процесів самої технології утворення піни і переважно пояснюємо двома причинами: зміною розмірів бульбашок та їх однорідністю.

Розміри бульбашок. Дрібні бульбашки мають більшу механічну міцність, з меншою "рихлістю". Для теоретичного обгрунтування цього факту було введено поняття умовної відносної міцності бульбашки як величину відношення площі центрального поперечного перетину бульбашки до ії маси бульбашки $\left(\kappa \Gamma^{-1} \mathrm{M}^{2}\right)$

$$
\begin{gathered}
k_{m}=\frac{S}{m}=\frac{\frac{\pi}{4} \cdot\left(D^{2}-d^{2}\right)}{\rho \cdot \frac{\pi}{6} \cdot\left(D^{3}-d^{3}\right)}=\frac{3 \cdot\left(D^{2}-d^{2}\right)}{\rho \cdot 2 \cdot\left(D^{3}-d^{3}\right)}= \\
=\frac{3 \cdot(D+d) \cdot(D-d)}{\rho \cdot 2 \cdot\left(D^{2}+D d+d^{2}\right) \cdot(D-d)}=\frac{3 \cdot(D+d)}{2 \cdot \rho \cdot\left(D^{2}+D d+d^{2}\right)},
\end{gathered}
$$

де: $S$ - площа центрального поперечного перетину бульбашки, м²; $m$ - маса бульбашки, кг; $D, d$ - зовнішній та внутрішній діаметр бульбашки, м; $\rho$ - густина суміші води 3 піноутворювачем, кг/ $\mathrm{M}^{-3}$.

Виходячи з визначення поняття коефіцієнта кратності, отримаємо рівняння:

$$
k_{F E R}=\frac{V_{\text {foam }}}{V_{\text {liq }}}=\frac{D^{3}}{D^{3}-d^{3}},
$$

де: $V_{\text {foam }}-$ об'єм піни, м ${ }^{3}, V_{l i q}-$ об'єм суміші води 3 піноутворювачем, м

Розв'язуючи систему цих двох рівнянь, отримаємо формулу для величини умовної відносної міцності бульбашки

$$
k_{m}=\frac{3 \cdot\left(1-\left(\frac{k_{F E R}-1}{k_{F E R}}\right)^{2 / 3}\right)}{2 \cdot D \cdot \rho \cdot\left(1-\frac{k_{F E R}-1}{k_{F E R}}\right)} \approx \frac{3}{2 \cdot D \cdot \rho}, \mathrm{K}^{-1} \mathrm{M}^{2} .
$$

Оскільки значення діаметра бульбашки знаходиться у знаменнику, то стає очевидно, що досліджувана умовна міцність бульбашки збільшується зі зменшенням діаметра бульбашки. Однорідність піни, тобто мала різниця розмірів бульбашок, що іiі утворюють, є другою характеристикою механічних властивостей піни. Відповідно до рівняння Юнга-Лапласа (Nikulin, Kodrik \& Titenko, 2018), величина тиску повітря всередині бульбашки обернено пропорційна іiі діаметра, тому під час контакту бульбашок різного розміру відбувається перетікання повітря 3 малої бульбашки у більшу з утворенням нової збільшеної бульбашки, яка внаслідок збільшення діаметра має меншу стійкість. Ми стверджували (Nikulin, Kodrik \& Titenko, 2018), що розміри бульбашок КП та їі однорідність для кожної конкретної установки залежать від методів утворення КП, типу і концентрації піноутворювача (далі ПУ), наявності в ньому стабілізаційних речовин, а також від співвідношення витрат водного розчину ПУ і повітря, повітряного тиску у системі подачі КП. Завдання дослідження - перевірити наведені вище припущення та встановити зв'язок між зміною розмірів бульбашок КП і їх однорідністю 3 експлуатаційними показниками піни, наприклад іï стійкістю. Як зазначено у (Nikulin, Kodrik \& Titenko, 2018), стійкість КП (y) пропорційна ії кратності $(x)$ :

$$
y=2,4732 x-15,538 \text {. }
$$

Враховуючи простоту визначення величини кратності піни, приймаємо ії надалі показник якості піни. У роботі використовували методики та обладнання, викладені (Nikulin, Kodrik \& Titenko, 2018). Для визначення реальних розмірів міхурів було проведено калібрування мікроскопа та цифрової камери залежно від кратності збільшення. Для калібрування використовували об'єкт-мікрометр, який є прозорим склом, на якому нанесено шкалу 1 мм (1000 мкм), з ціною поділки 0,01 мм (10 мкм).

Результати дослідження. Провели три серії дослідів для піни різної кратності: Серія №1 - за кратності піни 20; Серія № 2 - за кратності піни 12; Серія № 3 за кратності піни 6. Результати вимірів та оброблення даних навели у табл. 1 та 2 відповідно.

При цьому під $\bar{D}_{v f}$ приймаємо такий діаметр краплин, для якого частка $f$ загального об'єму рідини перебуває у вигляді краплин меншого діаметра. Як чисельну інтерпретацію полідисперсності приймали величину відносного стандартного відхилення, яку обчислювали за формулою

$$
S_{\text {rel }}=\frac{1}{\bar{D}_{10}} \cdot \sqrt{\frac{1}{N} \cdot \sum_{i=0}^{N-1}\left(D_{i}-\bar{D}_{10}\right)^{2}},
$$

де: $\bar{D}_{10}$ - величина середнього лінійного діаметра, мм; $D_{i}$ - результат оцінки величини діаметра $i$-го міхура, мм; $N$ - кількість міхурів певної серії дослідів (об'єм вибірки).

За результатами проведених досліджень побудували гістограми вибірок реальних розмірів бульбашок піни залежно від кратності піни, які навели на рис. 2. 
Табл. 1. Результати вимірів геометричних характеристик КП

\begin{tabular}{|c|c|c|c|c|c|c|c|c|c|}
\hline \multirow{3}{*}{ № 3/ח } & \multicolumn{3}{|c|}{ Кратність 20} & \multicolumn{3}{|c|}{ Кратність 12,5} & \multicolumn{3}{|c|}{ Кратність 5} \\
\hline & \multicolumn{2}{|c|}{ діапазон діаметрів, мм } & \multirow{2}{*}{$\begin{array}{l}\text { кількість } \\
\text { у виборці }\end{array}$} & \multicolumn{2}{|c|}{ діапазон діаметрів, мм } & \multirow{2}{*}{$\begin{array}{l}\text { кількість } \\
\text { у виборці }\end{array}$} & \multicolumn{2}{|c|}{ діапазон діаметрів, мм } & \multirow{2}{*}{$\begin{array}{l}\text { кількість } \\
\text { у виборці }\end{array}$} \\
\hline & $\min$ & $\max$ & & $\min$ & $\max$ & & $\min$ & $\max$ & \\
\hline 1 & 0,089 & 0,091 & 3 & 0,090 & 0,094 & 5 & 0,045 & 0,060 & 1 \\
\hline 2 & 0,091 & 0,093 & 1 & 0,094 & 0,099 & 4 & 0,060 & 0,075 & 5 \\
\hline 3 & 0,093 & 0,095 & 9 & 0,099 & 0,103 & 12 & 0,075 & 0,090 & 13 \\
\hline 4 & 0,095 & 0,097 & 11 & 0,103 & 0,108 & 15 & 0,090 & 0,105 & 24 \\
\hline 5 & 0,097 & 0,100 & 23 & 0,108 & 0,112 & 29 & 0,105 & 0,120 & 26 \\
\hline 6 & 0,100 & 0,102 & 20 & 0,112 & 0,116 & 15 & 0,120 & 0,135 & 13 \\
\hline 7 & 0,102 & 0,104 & 21 & 0,116 & 0,121 & 7 & 0,135 & 0,150 & 9 \\
\hline 8 & 0,104 & 0,106 & 7 & 0,121 & 0,125 & 10 & 0,150 & 0,165 & 11 \\
\hline 9 & 0,106 & 0,108 & 10 & 0,125 & 0,130 & 4 & 0,165 & 0,180 & 5 \\
\hline 10 & 0,108 & 0,111 & 2 & 0,130 & 0,134 & 1 & 0,180 & 0,196 & 1 \\
\hline \multicolumn{3}{|c|}{$\begin{array}{c}\text { Всього бульбашок у мм² } \\
\text { для серії №1 }\end{array}$} & 110 & \multicolumn{2}{|c|}{$\begin{array}{c}\text { Всього бульбашок у мм² } \\
\text { для серії №2 }\end{array}$} & 102 & \multicolumn{2}{|c|}{$\begin{array}{l}\text { Всього бульбашок у мм } \\
\text { для серії №3 }\end{array}$} & 108 \\
\hline
\end{tabular}

Табл. 2. Результати розрахунків статистичних характеристик КП

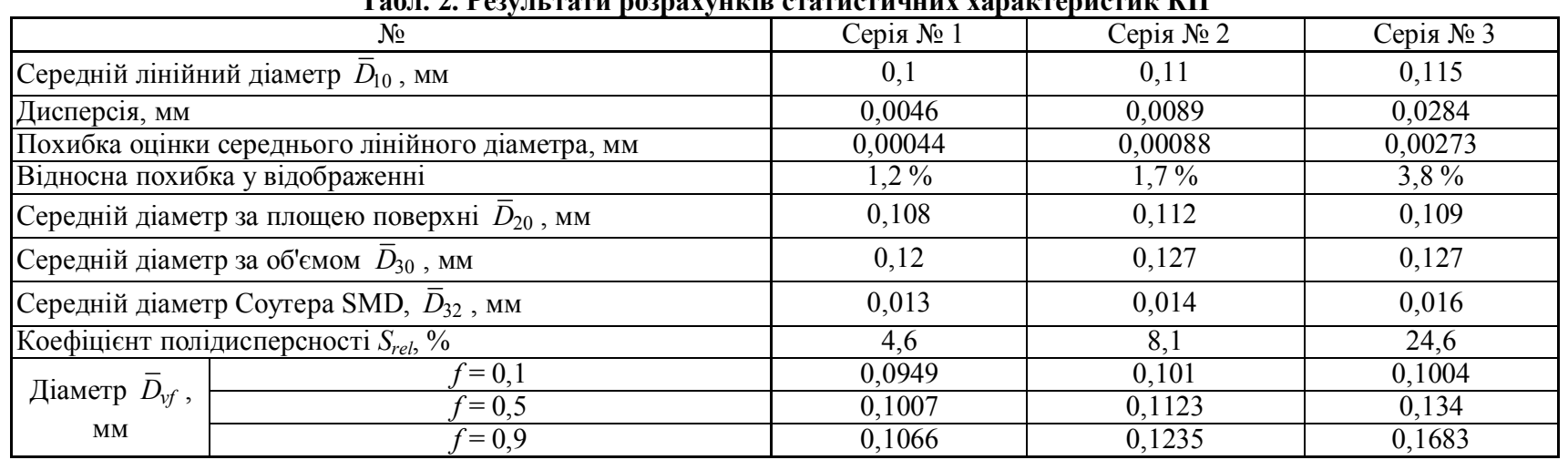
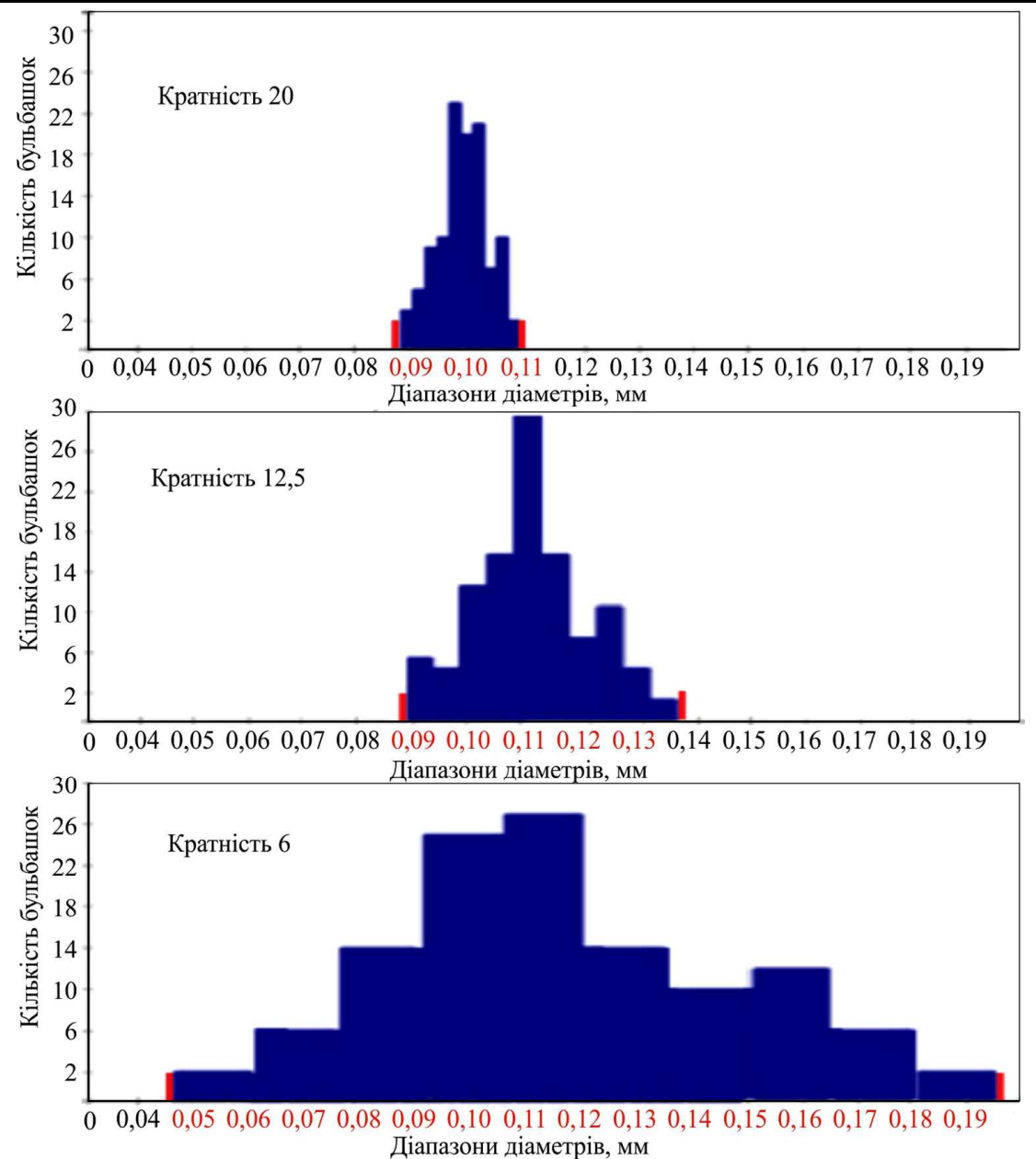

Pис. 2. Гістограми вибірок реальних розмірів бульбашок від кратності піни

Наведені гістограми підтверджують, що величини діаметрів бульбашок КП та їхня гомогенність, яка в нашому випадку характеризується полідисперсністю, виз- начають іï кратність, яка (Nikulin, Kodrik \& Titenko, 2018) визначає стійкість та адгезійні властивості піни. У разі збільшення кратності піни, полідисперсність 
зменшується, тобто однорідність зростає. Графік залежності полідисперсності піни від її кратності навели на рис. 3.

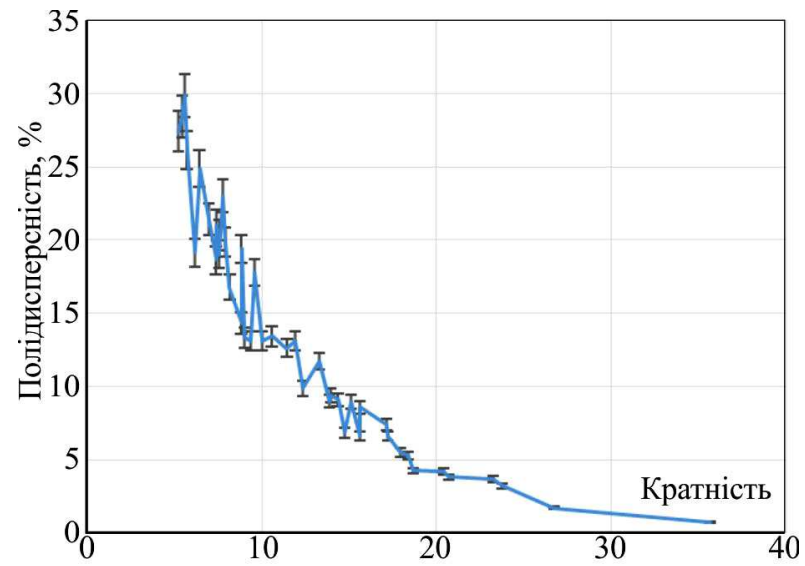

Рис. 3. Залежність полідисперсності піни від іiї кратності

Висновки. Аналізуючи викладений матеріал, можна зробити такі висновки:

1. Існує прямий зв'язок між експлуатаційними характеристиками КП, такими як: стійкість піни, адгезійна властивість піни, вогнегасна здатність піни та, іiі геометричними характеристиками - розмірами бульбашок та їх однорідністю, при чому розміри бульбашок та їхня гомогенність (полідисперсність) є визначальними параметрами компресійної піни щодо ії експлуатаційних характеристик.

2. Аналізуючи графічний матеріал, зазначимо, що однорідність, яка характеризується полідисперсністю піни, визначає їі кратність. У разі збільшення кратності піни, полідисперсність зменшується, тобто однорідність зростає.

3. Технологічні рішення, спрямовані на зменшення розміру бульбашок піни та підвищення iіï однорідності приз- ведуть до покращення експлуатаційних характеристик компресійної піни та іiі подальшого впровадження для боротьби з пожежами в лісних масивах на території України.

\section{Перелік використаних джерел}

Adamson, A. W., \& Alice P. Gast. (1997). Physical Chemistry of Surfaces. A Wiley-Interscience Publication.

CAFS. (2019). CAFS - straight answers for the beginner or the expericienced. Retrieved from: http://www.cafsinfo.com (accessed 05.03.2009)

Dorau, G., \& Kryuger, T. (2012). RU Patent № 2456037.

GOST R 50588. (2012). Penoobrazovateli dlya tusheniya pozharov. Penoobrazovateli dlya tusheniya pozharov. [In Russian].

Navrotskiy, O. D., et al. (2012). Penogeneriruyuschie sistemyi so szhatyim vozduhom - sredstvo pennogo pozharotusheniya novogo pokoleniya. Bulletin of the Command Engineering Institute of the Ministry of Emergency Situations of the Republic of Belarus, 1(15), 22-31. [In Russian].

Neal Brooks. (2019). Neal Brooks - compressed Air Foam Systems. Retrieved from: http://compressedairfoamsystem.com (accessed 12.03.2017).

Nikulin, O. F., Kodrik, A. I., \& Titenko, O. M. (2018). Provesti poshukovi doslidzhennya $\mathrm{z}$ vidpratsyuvannya skladu vognegasnoyi rechovini u viglyadi kompresiynoyi pini. Zvit pro naukovo-doslidnu robotu, UkrNDITsZ, DSNS Ukrayini. [In Ukrainian].

Nikulin, O. F., Kodrik, A. I., Titenko, O. M., \& Prisyazhnyuk, V. V. (2018). Rozroblennya eksperimentalnogo laboratornogo zrazka sistemi pinnogo pozhezhogasinnya, scho spozhivae stisnene povitrya. Naukoviy visnik: Tsivilniy zahist ta pozhezhna bezpeka, 2(6), 4-9. [In Ukrainian].

Taylor, R. G. (1997). Compressed Air Foam Systems in Limited Staffing Conditions. (Executive Development Research paper). Morristown, MD: National Fire Academy.

Zalesov, S. V., Godovalov, G. A., \& Krektunov, A. A. (2014). Sistema pozharotusheniya NATISK dlya ostanovki i lokalizatsii lesnyih pozharov. Sovremennyie problemyi nauki i obrazovaniya, 3. [In Russian].

\section{S. M. Shakhov', A. I. Kodryk', O. F. Nikulin², O. M. Titenko², S. A. Vinogradov', I. G. Stylyk ${ }^{2}$ \\ ${ }^{1}$ National University of Civil Protection of Ukraine, Kharkiv, Ukraine \\ ${ }^{2}$ Ukrainian Scientific Research Institute of Civil Defence, Kyiv, Ukraine}

\section{DETERMINATION OF THE DEPENDENCE OF COMPRESSION FOAM CHARACTERISTICS}

One of the promising ways to combat forest fires is considered. The authors suggest using compression foam as an extinguishing agent instead of ordinary water, which has several advantages. Unlike conventional foam, it has special properties that are not characteristic of the ordinary foam, such as increased stability, enhanced adhesion and fire extinguishing ability while reducing the flow of water and foaming agent. In order to increase the effective use of this extinguishing medium, we performed the theoretical substantiation of the dependence of operational characteristics of the compression foam depending on the geometric dimensions and homogeneity of the bubbles it is made up if. The notion of conditional relative strength of the bubble as a value of the ratio of the area of the central transverse section of the bubble to its bubble mass is introduced and the formulas for its deduction are given. The experimental dependences of the operational characteristics of the compression foam on the geometrical sizes and the homogeneity of the bubbles forming it, which will allow creating effective systems for the formation of a compressive foam, and controlling the processes of foaming and fire extinguishing, are presented. The results of the studies confirm that the values of the diameters of the bubbles of the compression foam and their homogeneity, characterized by the polydispersity of the foam, determine its multiplicity, which in turn determines the stability and adhesion properties of the foam. With an increase in the frequency of foam, the polydispersity decreases, i.e., homogeneity increases. It has been proved that there is a direct relationship between the operational characteristics of the compression foam such as the foam stability, the adhesive property of the foam, the fire-extinguishing ability of the foam and its geometric characteristics - the size of the bubbles and their homogeneity, in which the size of the bubbles and their homogeneity (polydispersity) are the determining parameters of compression foam for its performance. Technological solutions aimed at reducing the size of foam bubbles and enhancing their uniformity will lead to improved performance of the compression foam in order to increase the fire-extinguishing capabilities of the compression foam in the fight against forest fires.

Keywords: compression foam; bubble sizes; uniformity; foam stability; forest fires. 